\title{
Low-cost UAV as a Source of Image Data for Detection of Land Cover Changes
}

\author{
Pavel Sedlák ${ }^{1 *}$, Jitka Komárková ${ }^{1}$, Jakub Jech ${ }^{1}$, Oldřich Mašín ${ }^{2}$ \\ ${ }^{1}$ Faculty of Economics and Administration, University of Pardubice, Pardubice, CZECH REPUBLIC \\ ${ }^{2}$ Department of Crisis Management, Regional Authority of the Pardubice Region, Pardubice, CZECH REPUBLIC
}

*Corresponding Author: pavel.sedlak@upce.cz

Citation: Sedlák, P., Komárková, J., Jech, J. and Mašín, O. (2019). Low-cost UAV as a Source of Image Data for Detection of Land Cover Changes. Journal of Information Systems Engineering \& Management, 4(3), em0095. https:// doi.org/10.29333/jisem/5894

Published: August 26, 2019

\begin{abstract}
Data from remote sensing methods have been used successfully to monitor changes in the landscape. At present, unmanned aerial vehicles (UAVs) are also increasingly used. The article shows how to use the middle-class dron, specifically DJI Phantom 3 with a built-in camera, to monitor and document changes in the vicinity of small water bodies where a part of the shore is poorly accessible or totally unavailable. The obtained data can be further processed by conventional digital image processing methods such as image classification, highlighting through spectral indexes, or even visually comparing.
\end{abstract}

Keywords: image processing, UAV, land cover, detection of changes

\section{INTRODUCTION}

Landscape changes over time, both its horizontal and vertical structure changes. Changes can be caused by both anthropogenic and natural influences. (Forman and Godron, 1986) Changes in the landscape (land cover and land use) have been monitored in space and time using geoinformation technologies for a long time.

The aim of the article is to describe the process of using images from the middle-class dron, specifically DJI Phantom 3 with a built-in camera, to monitor and document changes in the vicinity of small water bodies. The article follows the work Sedlák, Komárková, Mašín and Jech (2019).

\section{PREVIOUS RESEARCHES}

Small water bodies represent a significant landscape element, and their importance is increasing today due to the increasing water shortage. Changes in the vicinity of small water bodies occur essentially constantly and need to be monitored.

\section{Small Water Bodies}

Water surfaces are considered to be continuous water covers on the body surface, which are relatively static in terms of flow. Different sources define small water bodies differently, and areas with an area up to $1-5$ ha are often considered to be small water bodies. The shoreline is the physical boundary between land and water. In fact, the position of the shoreline changes continuously over time for various reasons, for example, due to coastal zone sediment, bottom water, storm, and wave effects. The work monitored the changes in the coastal zone. Parts of the coastal zone are the water area, periodically flooded areas, and coastal vegetation. The periodically flooded area 
is referred to as the drawdown zone. The drawdown zone is the area at the edge of a water body that is frequently exposed to air due to changes in water level. Changes in water level can be caused by evaporation or water usage in the case of reservoirs. The drawdown zone is an extremely important habitat and has many plants and animals associated with it (Boak and Turner, 2005; Dolan, et al., 1980; List and Farris, 1999; Morton, 1991; Smith and Zarillo, 1990).

\section{Use UAV for Monitoring}

Remote sensing is very often used as a source of data for observation of landscape and terrain. There are many issues why this method is more reasonable than in situ observations, sampling and measurements, and land surveying. It means the costs are lower (namely in the case when bigger areas are monitored), accuracy and spatial resolution are adequate to aims of studies and finally, data measured in various parts of the electromagnetic spectrum are available. The last advantage is important for researches based on thermal imagery, various indices, etc. Satellites or aerial imagery is available for monitoring larger areas. Unmanned aerial vehicles (UAV) are increasingly used to monitor small areas, e.g. small water bodies (ponds) (Komarkova and Sedlak, 2018). UAVs can provide results faster and usually with higher spatial resolution. The main part of this case study is a study of small water bodies which are monitored by a UAV.

UAVs are increasingly used in many areas of human activity. The article Gorkovchuk, Gorkovchuk and Hutnyk (2017) describes the use of low-cost UAV photogrammetry for exploration for the mining of minerals in Ukraine. The reference Martínez, Sarabia and García (2014) deals with the use of drones for farm purposes. The monitoring of crop height and biomass is also addressed by Tumlisan, Bronsveld and Koeva (2018). The reference Karas (2013) monitors the use of UAS for the monitoring of flooded areas in the Czech Republic. Monitoring volcanoes is another way of using UAS. Monitoring of signs that prevent eruption in areas where volcanic activity occurs frequently is the key to protecting lives, livestock, and property (Amici and Turci, 2014). UAV for glacier study in the Canadian Arctic describes Whitehead (2010). The article Karas and Šafár (2017) describes the mapping of the railway network using UAS photogrammetry.

\section{CASE STUDY}

The processing of images from a low-cost UAV can be divided into several basic steps:

- Goal setting

- Selection of the area of interest

- Flight planning

- Data collection

- Data processing

- Visual interpretation (or automatic processing)

- Visualization

- Interpretation.

\section{Area of Interest}

Define Area of interest is located near the city of Pardubice in the Czech Republic. A part of the pond with the name "Skrrín" was monitored (Figure 1). The area lies northwest of Pardubice and is very rich in ponds. The area of interest is flat, lying approximately $220 \mathrm{~m}$ above sea level. In the work is monitored the change of the coastal zone, which part in our study are the water surface, drawdown zone, and coastal vegetation. Coastal vegetation includes vegetation including trees, dry reeds (including dry grass) and dry trees. The territory was interested in the fragmentation of the line and accessibility. For the final analysis was used a rectangular area of approximately 3 $827 \mathrm{~m}^{2}$, which includes only one coastline spur. 


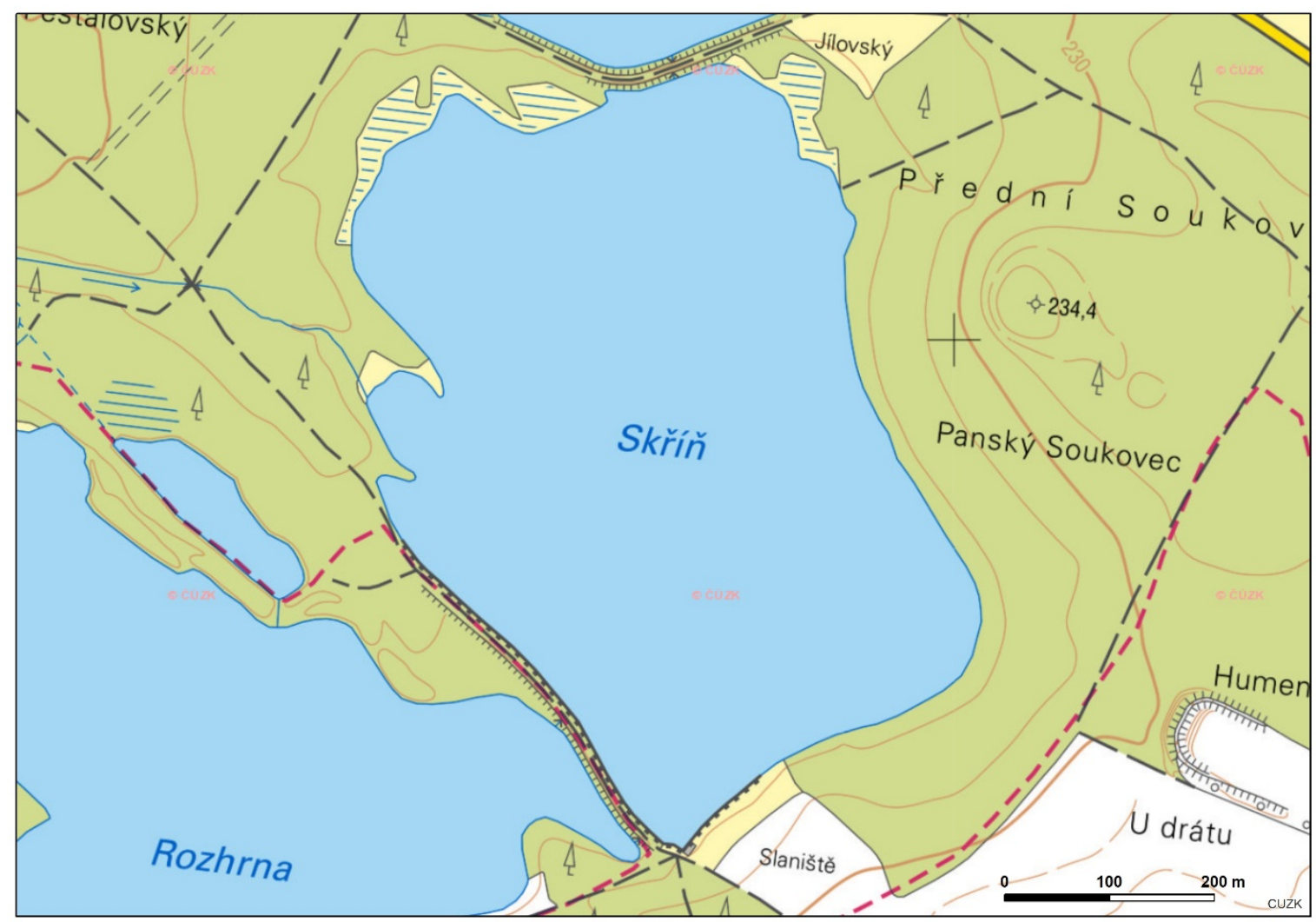

Figure 1. Map of the area of interest

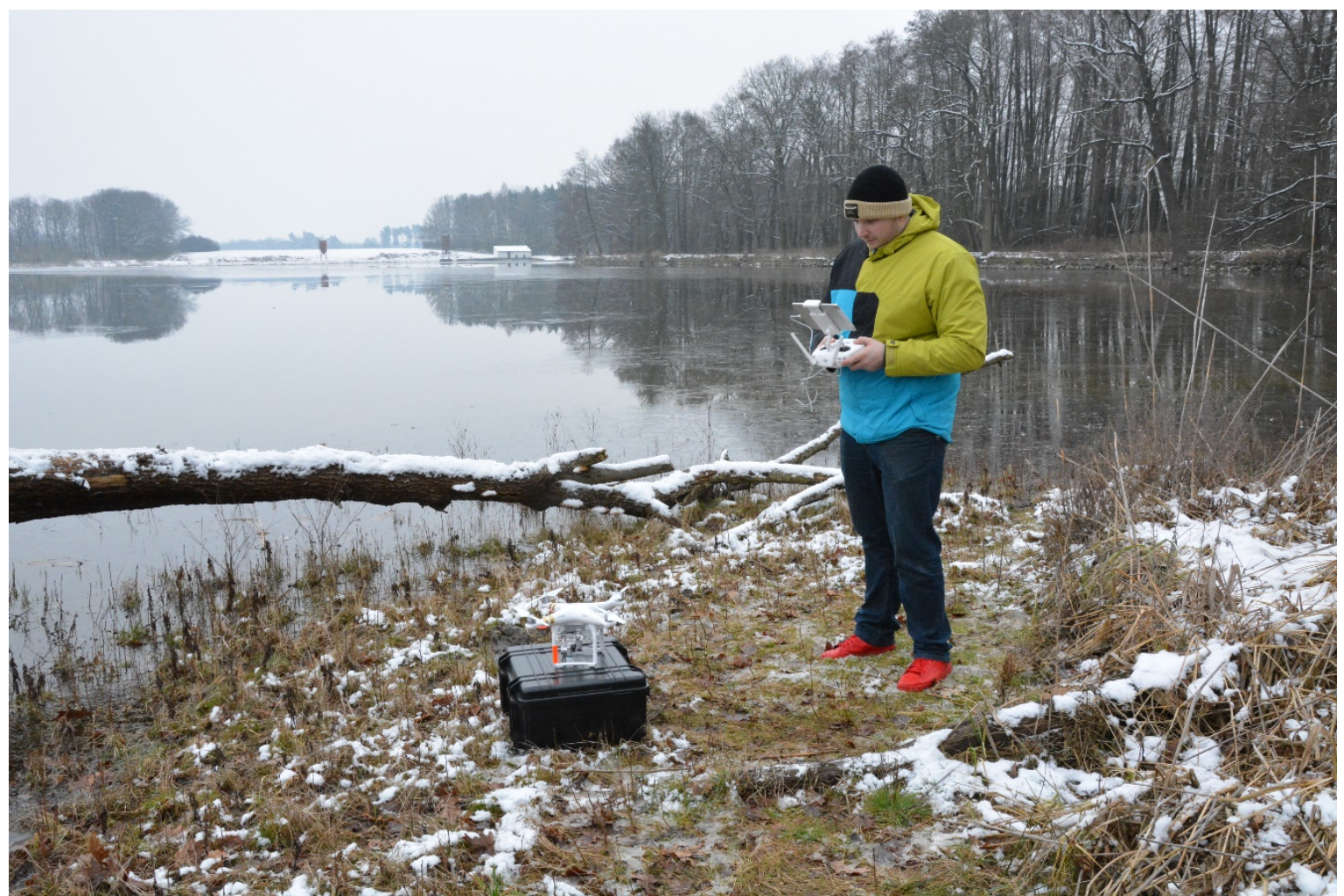

Figure 2. Phantom 3 on the shore of the area of interest before the flight (February 2018)

\section{Flight Planning and Data Collection}

The case study is focused on the utilization of a UAV for monitoring of the vicinity of small water bodies. Phantom 3 was used for monitoring (Figure 2). Because of UAV utilization, there is no multi-spectral data available, so many indices used to detect landscape changes cannot be used. UAV is equipped with a DJI camera 


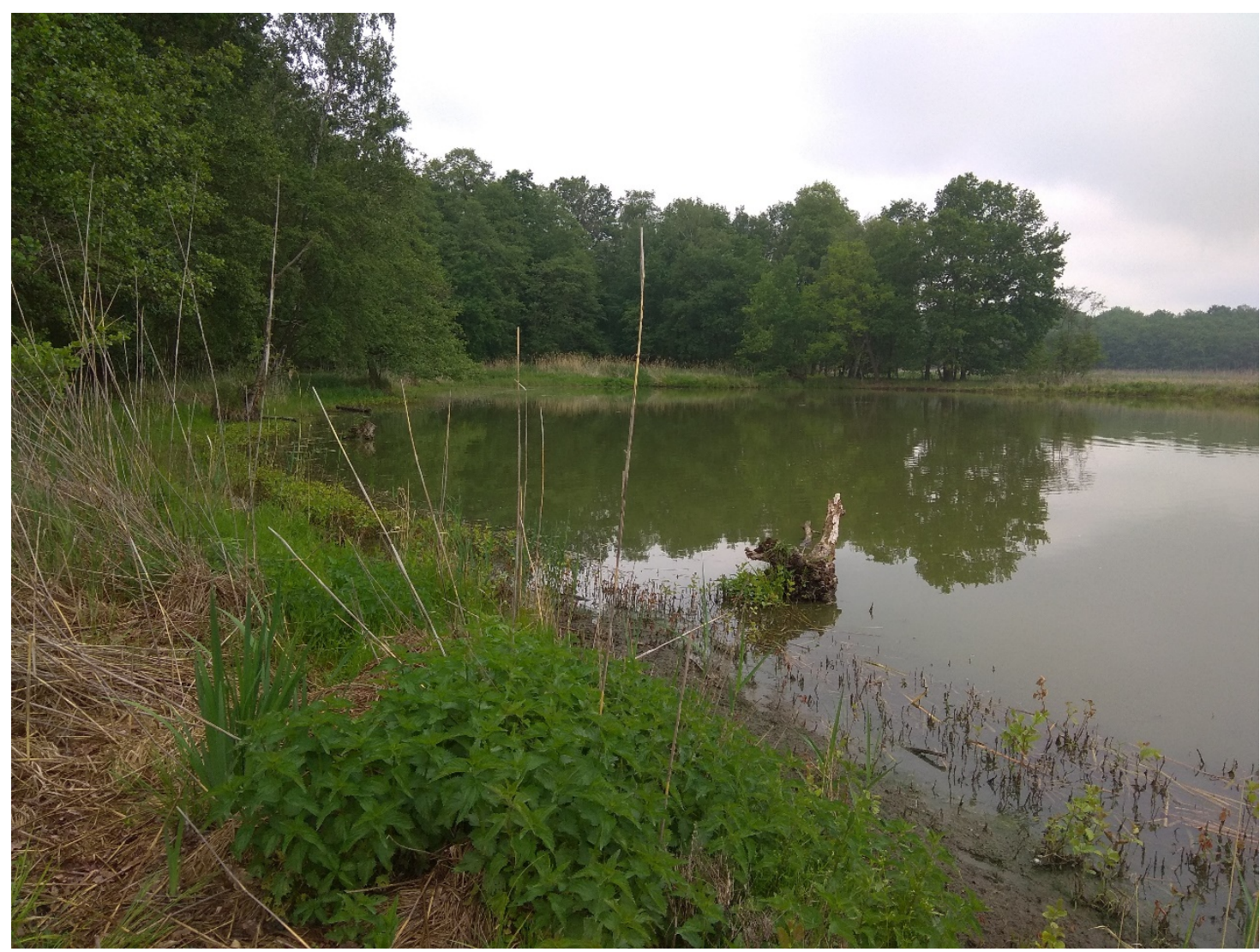

Figure 3. An image of the area of interest from May 2018

because no professional camera was available. A fast and cheap data collection with commonly available equipment is the main objective of this research.

An image of the area of interest from May 2018.Data sets were taken in eight-time horizons (February 9, 2018; March 8, 2018; April 5, 2018; April 20, 2018; May 11, 2018; June 27, 2018; July 31, 2018; August 22, 2018). The Phantom 3 has a mass of $1216 \mathrm{~g}, 4$ motors, a maximum climb speed of $5 \mathrm{~m} / \mathrm{s}$, a maximum descent speed of 3 $\mathrm{m} / \mathrm{s}$, a maximum speed of $16 \mathrm{~m} / \mathrm{s}$, max an available height of $6000 \mathrm{~m}$, a maximum range of $1000 \mathrm{~m}$ and a maximum flight time of about 25 minutes. Days were elected at almost a month's distance according to climatic conditions. The flight was scheduled in DJI GO and sent to the drones. Dron automatically flew as planned. Altitude was $39.6 \mathrm{~m}$ (February - April) and $61 \mathrm{~m}$ (May-August) due to better condition for mosaic procedure. Average speed was $2.2 \mathrm{~m} / \mathrm{s}$ (altitude 39.6) and 3.1 (altitude $61 \mathrm{~m}$ ). Data collection from the $0.0285 \mathrm{~km}^{2}$ area lasted approximately 15 minutes (altitude 39.6), so there was no need for a stop. Time of collection for bigger altitude was shorter. Front and side overlaps were $60 \%$.

\section{Data Processing}

Two software tools were used: Image Composite Editor (ICE) 2.0 and ArcGIS for Desktop 10.5.1. ICE was used to create a mosaic. WGS 84 - UTM Zone 33N was used as the coordinate system. ArcGIS was used for visual image interpretation, which was in the form of on-screen digitization. ArcGIS also has a final visualization of results, as this software provides sufficient tools for finalizing map outputs.

\section{Digitalization}

To analyze the change in the coastal zone at selected time horizons, it was important first to digitalize individual categories within all time horizons. Created mosaics for each time horizon (Figure 4) were cropped in the same area. For the final analysis, a rectangular area of approximately $1905 \mathrm{~m}^{2}$ was used which includes only one coastal part (Figure 5). The individual categories of the coastal zone were established at the beginning. The following categories were observed: water surface, ice, drawdown zone (periodically flooded areas), and coastal vegetation. Before digitization was necessary to create a polygon layer for each time horizon in ArcGIS. These layers were collected on-screen by digitizing the individual categories of the coastal zone. Created areas were subsequently added to the category ID. These ID numbers indicate the type of use of individual areas. The digitization process, of all time horizons, was very time-consuming. Figure 6 shows the digitization result of the one-time horizon. The next step was to calculate the area of each area. This procedure has been applied to all time horizons. The final results were interpreted. 

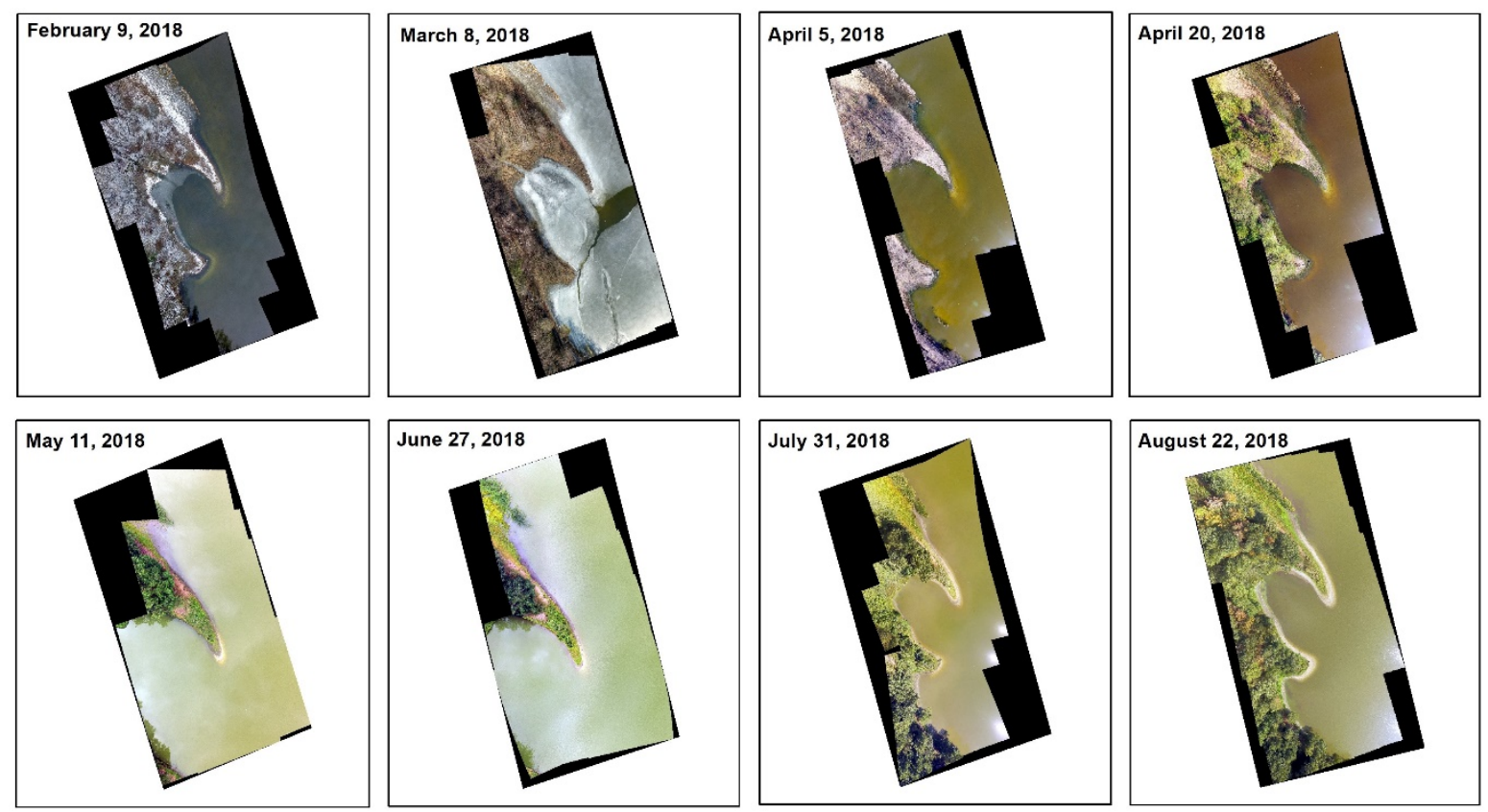

Figure 4. Mosaic images of monitored time horizons

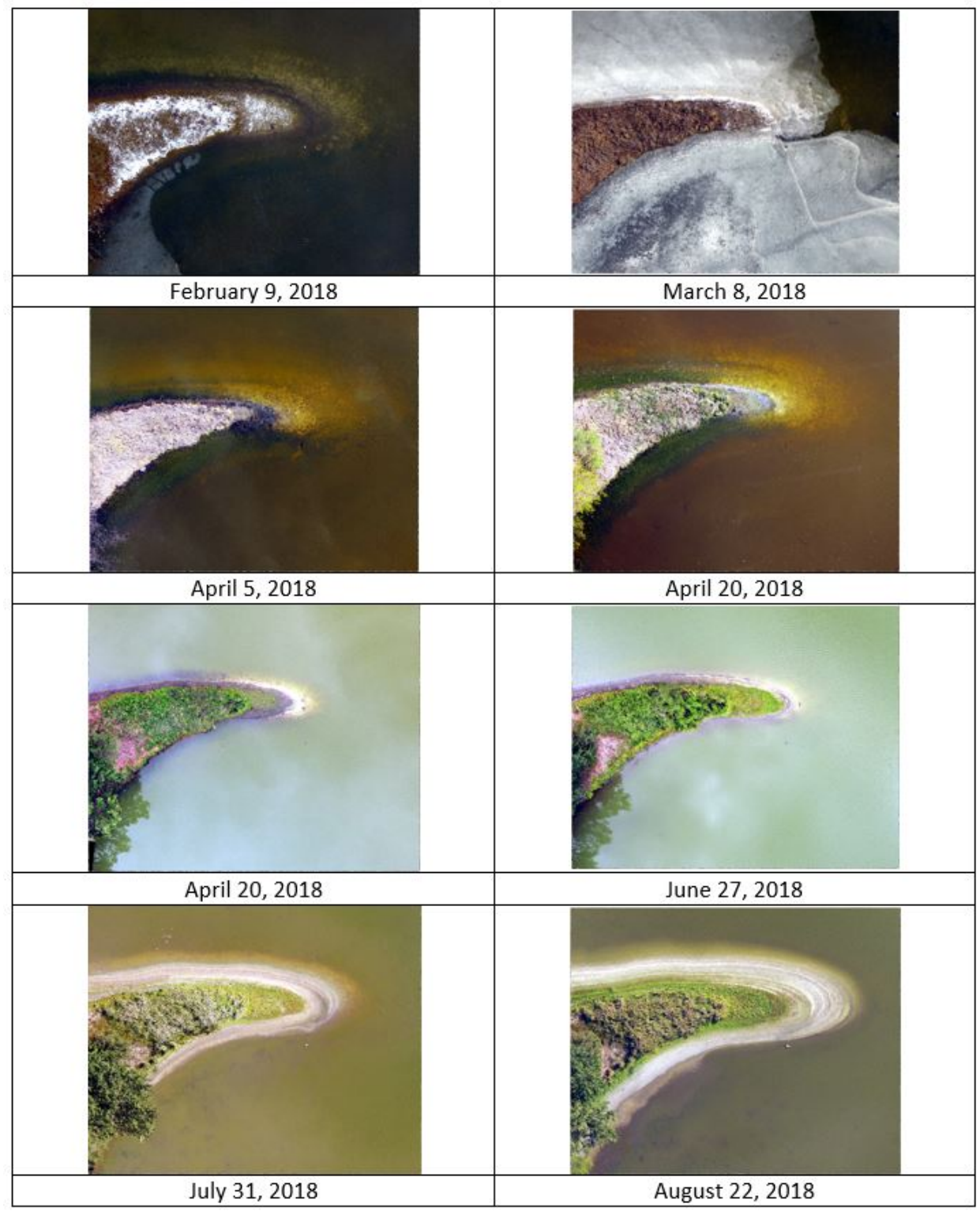

Figure 5. The final area of interest in individual time horizons 


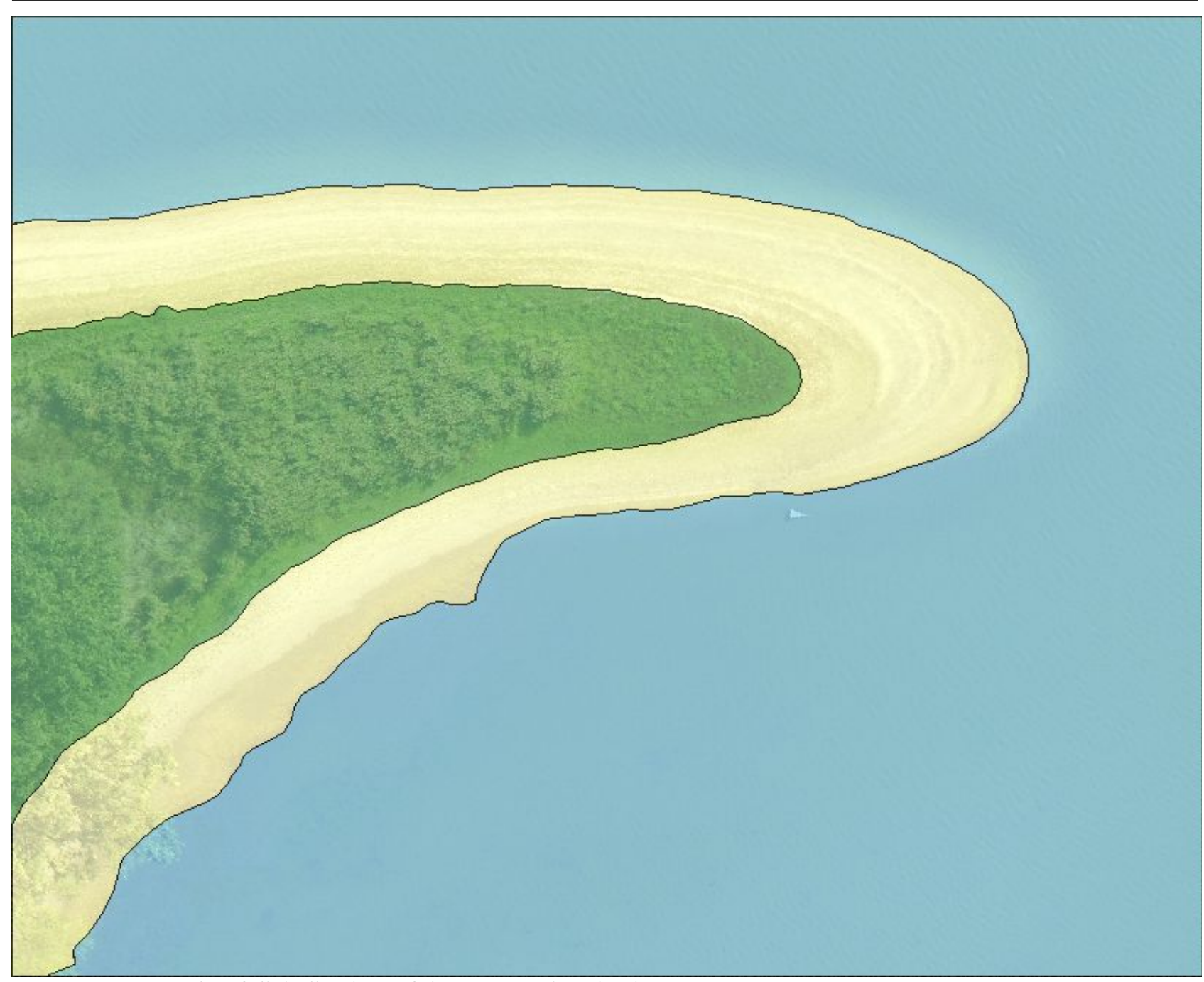

Figure 6. Example of digitalization of the August time horizon

\section{Interpretation of Results}

The resulting maps (Figure 7) illustrate the changes in the coastal zone in the first eight months of 2018. Table 1 shows the total category rating in individual time horizons in square meters. Table 1, Figure 7, and Figure 8 show that there were minimal changes at the beginning of the year. Bigger changes are evident during the summer months. Changes in the amount of vegetation and loss of water in the tank as a result of dry summer months are also apparent. These changes correspond with small amounts of precipitation. Images of February and March show ice on the water surface. The largest ice cover can be seen in the March picture. This situation corresponds with the smallest area occupies the water in the March picture because most of the surface is covered with ice. The smallest area occupies vegetation at the beginning of April. The water surface occupies the largest area on the image from the beginning of April because the last remnants of snow and ice on the stream were heated and melted, which is also evidenced by the increased water level. New vegetation is well visible from the end of April. The largest area is reached by coastal vegetation in August. Each category was very well interpretable due to its high spatial resolution from the drones. Tracking the territory continued in the months to come. 


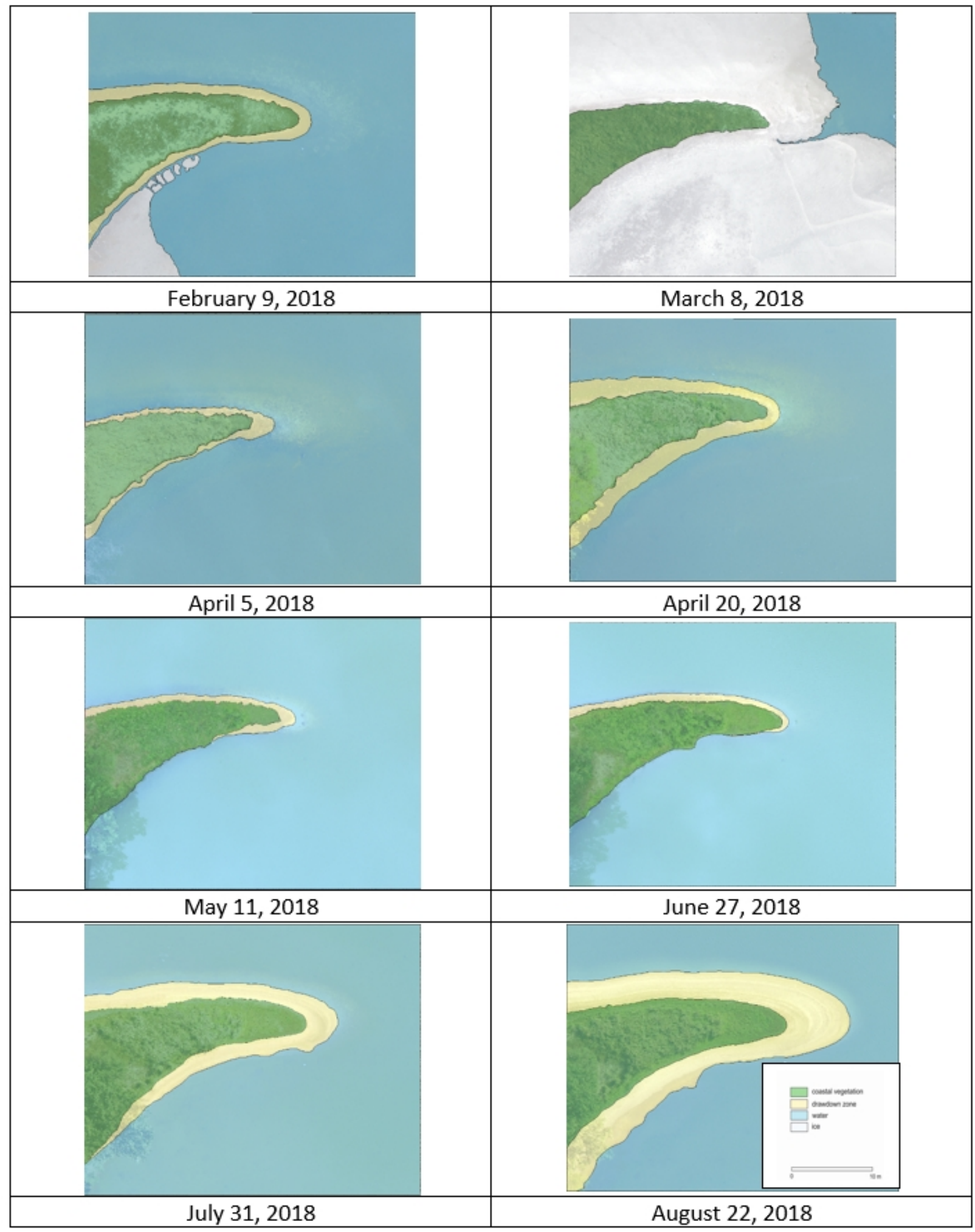

Figure 7. An image of the area of interest from May 2018

Table 1. Changes in the monitored categories in individual time horizons

\begin{tabular}{lcccccccc}
\hline Category/Month & February & March & April_B & April_E & May & June & July & August \\
\hline Coastal vegetation & 553.18 & 410.12 & 354.49 & 506.91 & 455.34 & 513.48 & 633.24 & 643.01 \\
\hline Drawdown zone & 194.48 & 0.00 & 102.74 & 312.18 & 82.05 & 77.16 & 353.14 & 744.08 \\
\hline Water & 2843.05 & 411.79 & 3369.24 & 3006.93 & 3290.03 & 3236.97 & 2840.04 & 2439.89 \\
\hline Ice & 236.43 & 3004.89 & 0.00 & 0.00 & 0.00 & 0.00 & 0.00 & 0.00 \\
\hline
\end{tabular}




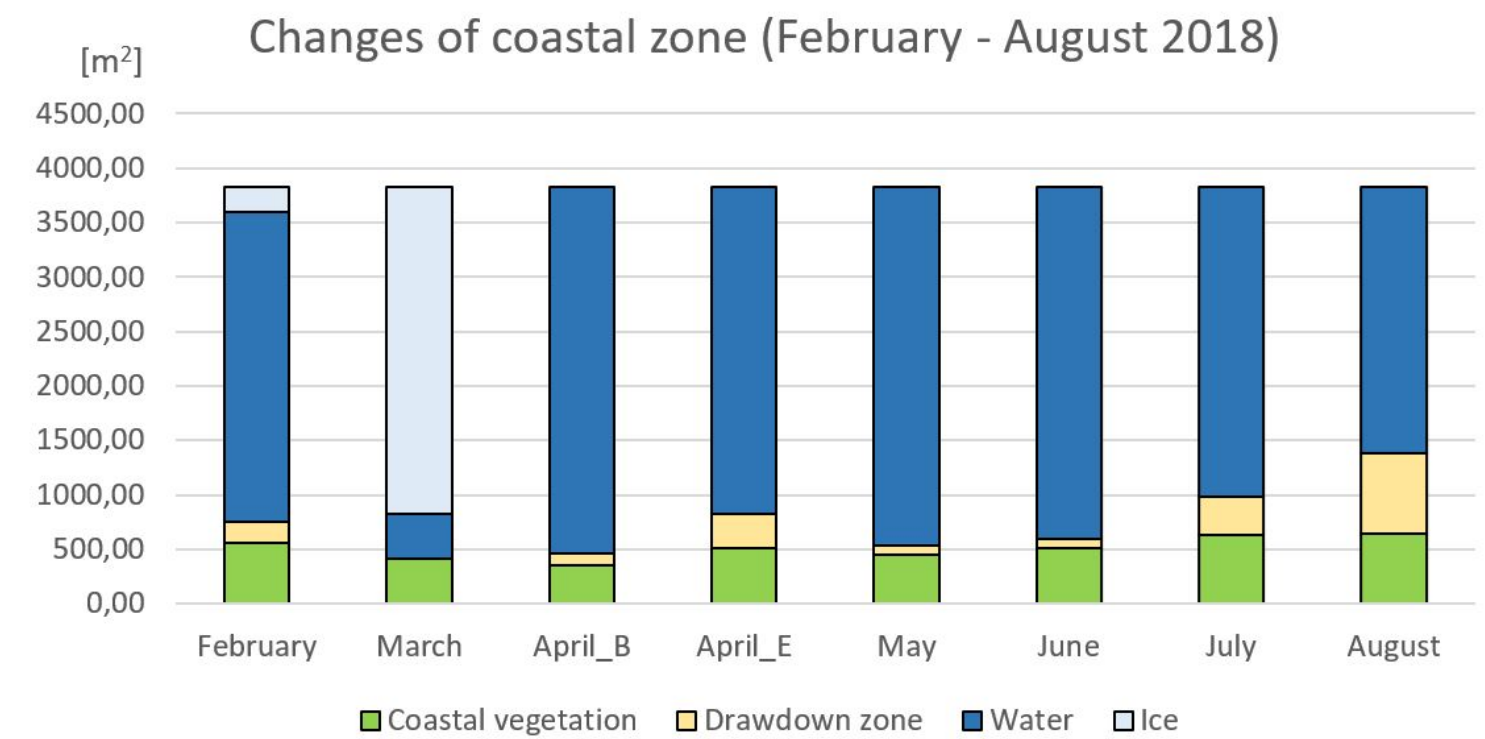

Figure 8. Changes in the monitored categories in individual time horizons

\section{CONCLUSIONS}

The monitoring of landscape changes based on remote sensing data belongs to a long-developing field. With the growing need to focus on small water areas, the use of UAVs is also important. Drones enable flexible monitoring of small areas, of course, while respecting legislation and current meteorological conditions. They provide data with very high spatial resolution. Depending on the sensor, the data can be scanned either in visible spectral bands or in other bands. Even data captured only in visible spectral bands can be used to identify changes in the landscape, e.g. based on visual interpretation of individual time horizons. The article describes the collection, visualization, and interpretation of data from a low-cost UAV and demonstrates their excellent usability in monitoring changes in the vicinity of small water bodies.

\section{ACKNOWLEDGEMENT}

Authors thank the University of Pardubice, Students grant competition, SGS_2019_17 project for the support.

\section{REFERENCES}

Amici, S. and Turci, M. (2014). Monitoring Vulcanoes with UAS: Testing the Suitability of Thermal Infrared Sensors. Available at: https://www.gim-international.com/content/article/monitoring-vulcanoes-with-uas (Accessed 13 February 2019).

Boak, E. H. and Turner, I. L. (2005). Shoreline Definition and Detection: A Review. Journal of Coastal Research, 21(4), 688-703. https://doi.org/10.2112/03-0071.1

Dolan, R., et al. (1980). The reliability of shoreline change measurements from aerial photographs. Shore and Beach, $48(4), 22-29$.

Forman, R. T. T. and Godron, M. (1986). Landscape ecology. New York, New York, USA: John Wiley and Sons.

Gorkovchuk, D., Gorkovchuk, J. and Hutnyk, B. (2017). Photogrammetry for Mining: Exploring Consumer-grade Copters for Quarry Mapping. Available at: https:/ /www.gim-international.com/content/article/low-cost-uas-photogram metry-for-mining?utm_source $=$ Newsletter+Superlist\&utm_campaign=5afc1de9b6-EMAIL_CAMPAIGN_ 2017_10_19GIM\&utm_medium=email\&utm_term=0_9bcc6040d6-5afc1de9b6-46151793 (Accessed 13 February 2019).

Karas J. and Šafár, V. (2017). UAS Photogrammetry and Railway Mapping: Pilot in the Czech Republic Attains High-precision Results. Available at: https://www.gim-international.com/content/article/uas-photogram metry-and-railway-mapping (Accessed 13 February 2019).

Karas, J. (2013). UAS and Flooding: Monitoring Flooding and Assessing Damage in the Czech Republic. Available at: https://www.gim-international.com/content/article/uas-and-flooding (Accessed 13 February 2019). 
Komarkova, J. and Sedlak, P. (2018). UAV Spectral Image Mapping of Shoreline Vegetation. GIM International-The Worldwide Magazine for Geomatics, 32(6), 26-27.

List, J. H. and Farris, A. S. (1999). Large-scale shoreline response to storms and fair weather. Proceedings of the Coastal Sediments, pp. 1324-1337.

Martínez, D., Sarabia, A. and García, S. (2014). UAS in Farming: A Pilot Project in Cuba. Available at: https:/ /www.gim-international.com/content/article/uas-in-farming (Accessed 13 February 2019).

Morton, R. A. (1991). Accurate shoreline mapping: past, present, and future. Proceedings of the Coastal Sediments, pp. 997-1010.

Sedlák, P., Komárková, J. Mašín, O. and Jech, J. (2019). The Procedure for Processing Images from a Low-cost UAV The Case of Monitoring Landscape Changes. In 14th Iberian Conference on Information Systems and Technologies (CISTI), pp. 1-4, IEEE. https:// doi.org/10.23919/CISTI.2019.8760952

Smith, G. L. and Zarillo, G. A. (1990). Calculating long-term shoreline recession rates using aerial photographic and beach profiling techniques. Journal of Coastal Research, 6(1), 111-120.

Tumlisan, G., Bronsveld, K. and Koeva, M. (2018). UAS-based Measurement of Crop Height and Biomass: Monitoring Crop Growth and Estimating Yield Production in Precision Farming. Available at: https://www.giminternational.com/content/article/uas-based-measurement-of-crop-height-and-biomass?utm_source=

Newsletter+Superlist\&utm_campaign=4b43b3d340-EMAIL_CAMPAIGN_2018_01_25GIM\&utm_medium =email\&utm_term=0_9bcc6040d6-4b43b3d340-46151793\&mc_cid=4b43b3d340\&mc_eid=8e06fb45f3 (Accessed 13 February 2019).

Whitehead, K. (2010). Unmanned Aerial Vehicles for Glaciological Studies: Airborne Survey of Fountain Glacier's Terminus Region. Available at: https://www.gim-international.com/content/article/unmanned-aerial-vehicles-forglaciological-studies (Accessed 13 February 2019). 